\title{
A RECOMPOSIÇÃO DA HISTORIOGRAFIA FRANCESA APÓS A CRISE DE HEGEMONIA DOS ANNALES
}

\section{Rodrigo Bianchini Cracco ${ }^{1}$}

A história social-econômica dos Annales orientou a historiografia francesa ao longo de grande parte do século XX. Em oposição à produção majoritariamente política da Escola Metódica, os annalistes buscaram ressaltar os aspectos coletivos e de longa duração dos processos históricos. Os materiais eleitos como documentação e a forma de trabalho destes historiadores favoreciam olhares mais dedicados às graduais oscilações da vida social. Os ciclos econômicos também são evidenciados pela manipulação de longas séries documentais. Apesar de terem produzido trabalhos de história cultural e política, o social-econômico foi predominante.

Nas décadas finais do século XX, pode-se observar como a pluralização dos modos explicativos e compreensivos da história levou ao enfraquecimento de grandes modelos historiográficos dominantes, em especial o dos Annales e do marxismo. Essa crise de hegemonia dos Annales confundiu-se com uma mutação mais geral do pensamento histórico, muitas vezes chamada de "crise da história".

A historiografia francesa não se reduz ao grupo dos Annales. Esta falsa indução, contudo, não deve olvidar a necessidade de renovação e a disputa pelo espaço político e institucional deixado pela história social-econômica, disputa essa que excede o quadro das fileiras da Nova História. Em vista disso, buscaremos analisar as particularidades de quatro áreas do campo historiográfico em seus esforços de renovação e apropriação: política, do tempo presente, cultural e social. A eleição dessas áreas em detrimento de outras se dá em função da envergadura das publicações $e$ autores envolvidos $e$, principalmente, por apresentarem estados anteriores bem definidos, de forma que as atualizações se destacam mais claramente.

Um elemento em comum que pudemos observar nas quatro áreas é a renovação dos quadros teóricos disciplinares. Dentre as diversas matrizes para essa renovação, buscaremos destacar uma em especial: a apropriação da obra de Paul Ricoeur pelos historiadores, como forma de fundamentar teoricamente o ofício na chamada "crise da história". Nosso objeto, portanto, está definido nos moldes de uma investigação historiográfica e teórica. Para tanto, nos ocuparemos essencialmente das obras de caráter programático de cada uma das áreas, articuladas com as análises de Ricoeur sobre o quadro atual da historiografia francesa após o período de domínio dos Annales.

${ }^{1}$ Doutor em História pela Universidade Federal de Minas Gerais - UFMG. Professor adjunto da Universidade Estadual de Mato Grosso do Sul. E-mail: cracco2011@gmail.com. 


\section{História Política}

Já no início da década de 1970, a história política mostra sinais de recuperação. Jacques Le Goff e Pierre Nora são os annalistes que então se apresentam ao debate. Em Is Politics Still the Backbone of History?, Le Goff faz referência aos avanços da história política numa linha típica de pensamento dos Annales. é, segundo ele, da contribuição da sociologia e da antropologia que ela se nutre para crescer. Nora $^{3}$ busca relacionar os retornos dos eventos e da história política como intimamente ligados às análises dos temas privilegiados pela história contemporânea. De fato, os eventos da segunda metade do século XX impuseram à história a abordagem política. O fim da divisão da Alemanha e o desmembramento da União Soviética propiciou aos historiadores uma enxurrada de arquivos para a análise de regimes políticos até então pouco acessíveis. Um vasto número de trabalhos acerca da reavaliação do papel ideológico do socialismo no leste europeu propiciou à história política um desenvolvimento capital em torno do conceito de culturas políticas.

As décadas de 1980 e 1990 marcaram a forte reabilitação da história política, em grande parte pela publicação da obra-chave Para uma história política dirigida por René Rémond (1988) ${ }^{4}$. Tendo em vista a história do século XX, Rémond propõe que a própria experiência mostrou a necessidade desta abordagem. O grupo dos Annales, em especial Fernand Braudel, infligiu duras críticas à história política, condenando o caráter subjetivo e episódico, de curta duração, das obras sobre os chefes de Estado, reis e outras figuras históricas 'centrais'. No texto que abre a obra Para uma história política, Rémond afirma que a história política que se passa a produzir no final do século XX não é uma volta aos procedimentos e problemáticas do início do século, tão criticados pelos annalistes, mas uma abordagem que parte das experiências nodais do mundo contemporâneo, tal como listadas pelo autor ${ }^{5}$. É o próprio século XX que impõe não um retorno, mas uma nova história política.

Rémond, na introdução do último volume de Histoire de France, coleção organizada por Jean Favier e publicada no mesmo ano de Para uma história politica, debate como as questões do Notre siècle, 1918-19956 (título do último volume da coleção), colocam a história política ao lado da história do tempo presente. Essa relação entre o presente e o político torna-se, como veremos, um dos principais traços distintivos da nova história política. Pierre Nora, já em $1974^{7}$, afirmou que a nova história política estava vinculada ao contemporâneo. Diversos outros elementos coincidiram para que seu prognóstico se mantivesse válido por décadas.

\footnotetext{
${ }^{2}$ LE GOFF, Jacques. Is Politics Still the Backbone of History? Daedalus. Vol. 100, n. 1, Historical Studies Today (Winter, 1971), p. 1-19.

${ }^{3}$ NORA, Pierre. O retorno do fato. In: LE GOFF, Jacques; NORA, Pierre (dir.). História: novos problemas. 4 ed. Trad. Theo Santiago. Rio de Janeiro: Francisco Alves, 1995 p. 179-193. (1 ed. de 1974).

${ }^{4}$ RÉMOND, René (dir.). Por uma história política. 2 ed. Trad. Dora Rocha. Rio de Janeiro: FGV, 2003. (1 ed. Francesa de 1988).

${ }^{5}$ Cf. RÉMOND, Por uma história política..., p. 23-25.

${ }^{6}$ RÉMOND, René; SIRINELLI, Jean-François (org.). Notre Siècle: 1918-1995. Paris: Fayard, 1991. (Tomo 6 da coleção Histoire de France, sob a direção de Jean Favier).

${ }^{7}$ NORA, Pierre. O retorno do fato..., p. 180.
} 
O filósofo francês Paul Ricoeur remete a este debate desenvolvido por Rémond para articular política e contemporaneidade. Segundo ele, as questões políticas do contemporâneo, tal como abordadas por Rémond, remetem ao sensível equilíbrio entre interpretação e busca da verdade histórica, tendo em vista que o "espaço" temporal entre o objeto histórico e sua análise ainda não se transformou em transmissão. Assim, o trabalho com os arquivos e os testemunhos dos agentes históricos envolvidos nos eventos traumáticos do Breve Século pode colocar em choque o engajamento político, sem dúvida, primordial, e o distanciamento crítico.

As dissensões entre memória e história, longamente abordadas por Ricoeur em $A$ memória, a história, o esquecimento, agem sobremaneira na história política. Acompanhando os argumentos de Rémond, Ricoeur ${ }^{8}$ caracteriza a contemporaneidade e o inacabamento do período abordado como as singularidades da nova história política e, como consequência, a forma como a dimensão de retenção da memória não dá tempo ao trabalho de luto. Assim, a história política fica cindida entre o passado imperfeito do que era, ainda vivo, e o tendo sido, passível de ser sepultado pela operação historiográfica. A nova história política não constrói túmulos para os mortos, mas estabelece interpretações historiográficas paralelamente, em consonância ou não, com o reconhecimento da memória.

Um pressuposto que marca toda a obra Para uma história política é a relativa autonomia da política em relação às outras categorias da sociedade: a política não é apenas efeito institucional do social, mas uma modalidade deste, assim como não é também uma regulação legitimadora dos movimentos econômicos. As instituições, os poderes e os sujeitos agentes do político constituem uma força relacionada, mas não subordinada, a qualquer outro domínio. Ricoeur reconhece essa autonomia do político na obra de Rémond desde a publicação de Les Droites em France ${ }^{9}$ (1982). Segundo Ricoeur "a principal pressuposição é a de uma autonomia das ideias políticas compatível com a variabilidade temática dos critérios de pertencimento (liberdade, nação, soberania)" 10 .

Às críticas à superficialidade da política, tal como esta era caricaturada pelos Annales, Rémond propõe atribuir a ela um papel diretor: "como sustentar ainda que o político não se refere às verdadeiras realidades, quando ele tem por objetivo gerilas?" ${ }^{11}$. A ênfase nas características centralizadoras da história política é uma constante

8 Vale notar que Rémond e Ricoeur não apenas debatem temas comuns da política como compartilharam a experiência da Revolução estudantil de 1968 em Nanterre. Charles Mercier, no artigo publicado na revista Vingtième Siècle intitulado René Rémond à Nanterre em 1968 (2009), coloca que Rémond adotou inicialmente uma postura dura e repreensiva em relação ao movimento, depois se distanciou e, por fim, buscou estabelecer um diálogo com os estudantes. Já Paul Ricoeur, Alain Touraine e Guy Michaud foram bastante favoráveis ao movimento. Contudo, Ricoeur foi posteriormente eleito doyen da faculdade e, sob sua responsabilidade, ocorreu intervenção policial no campus de Nanterre, que desembocou na ação violenta da polícia contra os estudantes. Ricoeur, apesar de ter sido um dos principais incentivadores do movimento meses antes, acabou por ficar conhecido como o "diretor que chamou a polícia", "racista e policial", "velho palhaço", entre outros (REIS, José Carlos. História da "consciência histórica" ocidental contemporânea: Hegel, Nietzsche, Ricoeur. Belo Horizonte: Autêntica, 2011. p. 241-243).

${ }^{9}$ REMOND, René. Les Droites em France. Paris: Aubier, 1982.

${ }^{10}$ RICOEUR, Paul. A memória, a história, o esquecimento. Tradução: Alain François [et al.]. Campinas: Unicamp, 2007, p. 239.

${ }^{11}$ REMOND, Por uma história política..., p. 24. 
na obra. No primeiro capítulo do livro, intitulado "Uma história presente", Rémond destaca que a reabilitação da história política está intimamente relacionada ao movimento de reflexão acerca do próprio ofício que ventila as preocupações dos historiadores nas últimas décadas. Portanto, é tanto da experiência política do século passado quanto da reelaboração interna da disciplina que a história política se alimenta e passa assim a almejar uma posição de abordagem predominante.

Numa passagem exemplar, Rémond articula retoricamente um misto de cautela $e$ afirmação, para enfatizar o papel do político:

$\mathrm{O}$ historiador do político não reivindica como objeto de sua atenção preferencial essa hegemonia: não pretende que tudo seja político, nem terá a imprudência de afirmar que a política tem sempre a primeira e a última palavra, mas constata que o político é o ponto para onde conflui a maioria das atividades e que recapitula os outros componentes do conjunto social. ${ }^{12}$

A reivindicação de hegemonia do político é substituída por sua constatação: à negatividade da primeira parte da frase segue-se um reconhecimento do papel central da política, que emana da experiência real. A confluência, na esfera política, dos elementos que compõem o social é assim uma atestação e síntese do conjunto social.

A maior parte dos desenvolvimentos da história política nas décadas de 1980 e 1990 se dá a partir do conceito de culturas políticas. As representações e os comportamentos políticos são o objeto das pesquisas em torno desta noção bastante abrangente e múltipla. É a partir do pluralismo interpretativo característico do final do século XX que a fusão cultura-política passa a se afirmar como campo renovado. Dois pressupostos da "antiga" história política são rejeitados em favor do pluralismo: o primeiro é o da crença em uma cultura política nacional homogênea e, o segundo, de uma hierarquia das culturas políticas, segundo a qual uma determinada forma de estrutura representativa seria mais adequada que outras. Numa mesma sociedade coexistem diversas culturas políticas. A tensão entre elas cria tanto a oposição partidária quanto entre os cidadãos não filiados. As culturas republicana, socialista, nacionalista, comunista, social-cristã, e diversas outras competem para a formação política tanto em nível social, de grupos que estabelecem laços em função do tema político, quanto individualmente, na medida em que cada individuo está exposto a todas elas, pelas mais diversas vias. A pluralidade de culturas políticas é proporcional à multiplicidade de matrizes de constituição social: a família, a escola, o trabalho, os partidos políticos, a mídia, as religióes, as mídias sociais, enfim, os diversos ambientes institucionais funcionam como propagadores de culturas políticas diversas, por vezes divergentes.

A nova história política é um tipo de contraponto à história social, pautada por referências diversas provenientes da sociologia, em especial de Norbert Elias e Pierre Bourdieu. As formações sociais fixas da história social que prevaleceram ao longo do século XX são substituídas por uma fluidez dos capitais simbólicos no processo de

${ }^{12}$ RÉMOND, Para uma história política..., p.447, grifo nosso. 
formação dos grupos sociais, mas é no indivíduo que a história política encontra a atualização do social. A proposta de que os poderes criam campos sociais nos quais estão em disputa capitais específicos e transferíveis encontra sua efetuação nos indivíduos que incorporam, no modelo do habitus de Bourdieu, as disposições compartilhadas que caracterizam cada cultura política.

O texto "A cultura política", de Serge Berstein, publicado na obra Para uma história cultural, apresenta bem essa tendência. Segundo o autor, determinada cultura política

[...] adquire-se no seio do clima cultural em que mergulha cada indivíduo pela difusão de temas, de modelos, de normas, de modos de raciocínio que, com a repetição, acabam por ser interiorizados e que o tornam sensível à recepção de ideias ou à adopção de comportamentos convenientes. ${ }^{13}$

A ênfase na determinação do comportamento individual pela cultura política é o tema central do texto de Bernstein. A adoção de determinada cultura política é primeiramente um fenômeno individual, que secundariamente é compartilhado por um grupo social. Nesse sentido, a nova história política busca renunciar às predefinições estruturais. Por outro lado, caracteriza-se pela ênfase na estratégia de adoção das culturas políticas pelos sujeitos, deixando assim pouco espaço para os acasos e inconsistências da experiência. Ainda que Rémond atribua um lugar à contingência, ao debater a questão do retorno dos eventos ao discurso do historiador, não são todos os historiadores do político que se dedicam às indeterminações da experiência, como é o caso do próprio Bernstein.

Os contatos entre a abordagem política e cultural são de extrema importância para a história política renovada. A contribuição de Bernstein à obra Para uma história política é de 1997. No ano seguinte, Sirinelli retribui a colaboração com um texto incluído na coletânea de trabalhos organizada por Bernstein e Pierre Milza, intitulada Axes et méthodes de I'histoire politique ${ }^{14}$. Tanto Sirinelli quanto Jean-Yves Mollier dedicam seus textos, na coletânea, ao debate acerca dos ganhos recíprocos da aproximação entre cultura e política.

\section{História do Tempo Presente}

Um elemento decisivo para a consolidação da nova história política é o fortalecimento do debate acerca da história do tempo presente. Henry Rousso, um dos grandes nomes dessa perspectiva historiográfica afirma que "[...] a escolha do termo História do Tempo Presente foi simplesmente para se destacar do termo História Contemporânea que, na França, possui outra significação" ${ }^{15}$. Rousso

\footnotetext{
${ }^{13}$ BERSTEIN, Serge. A cultura política. In: RIOUX, Jean-Pierre; SIRINELLI, Jean-François (dir). Para uma história cultural. Trad. Ana Moura. Lisboa: Estampa, 1998. p. 349-363. p. 357.

${ }^{14}$ BERSTEIN, Serge; MILZA, Pierre (dirs). Axes et méthodes de l'histoire politique. Paris: PUF, 1998.

${ }^{15}$ ROUSSO, Henry. Sobre a história do tempo presente: entrevista com o historiador Henry Rousso. Tempo e Argumento. Florianópolis, v. 1, n. 1, p. 201-216, jan./jun. 2009, p. 203.
} 
argumenta que o termo História Contemporânea tornou-se muito amplo. Qualquer pesquisa que considere o século XIX, XX ou XXI se encaixaria sob a égide de história contemporânea. Segundo o autor, essa divisão é tipicamente francesa, mas o Brasil e outros países seguem também esse marco para definir a história contemporânea ${ }^{16}$.

Rousso publicou em 2012 a obra La Dernière Catastrophe: L'histoire, le présent, le contemporain ${ }^{17}$, na qual busca estabelecer o alcance e os limites da história do tempo presente. Apesar de o autor relativizar o propósito da obra na introdução (p. 23), trata-se de um livro que compila os avanços conquistados na área nas décadas anteriores. Ao definir as especificidades da história do tempo presente, ele elabora um inventário das dificuldades de trabalhar com a historicidade do próprio presente, no qual o passado se mantém aberto e os personagens históricos ainda estão aqui. A argumentação do autor segue no sentido de inserir os acontecimentos mais recentes num processo de longa duração por meio do trabalho de "remontar o tempo de maneira regressiva" ${ }^{18}$. Toda história do tempo presente é, segundo ele, balizada pela última catástrofe, seja ela a mais influente no momento ou a mais recente cronologicamente. Essa forma de encarar o último século como uma sucessão de catástrofes é uma das características essenciais dessa vertente historiográfica, como abordaremos na sequência. Segundo Rousso, o aumento do interesse pela história do tempo presente não é um sintoma do regime de historicidade presentista, mas antes uma reação a ele. Historicizar o presente se torna assim uma função dos historiadores. Restabelecer os vínculos entre passado e presente passa necessariamente pelo reconhecimento da história não apenas como alteridade, mas também como elemento constituinte do presente.

Os diretores do Instituto de História do Tempo Presente, entre eles Henry Rousso e François Bédarida, buscam não apenas legitimá-la como campo válido e promissor para o historiador, ao se colocarem contra o pressuposto de que o tempo presente é tema apenas para os cientistas políticos e jornalistas, como também afirmam que essa abordagem é tão clássica quanto o próprio conhecimento histórico. Remetem a Heródoto e Tucídides para legitimar a tese de que em seu nascimento a história já era "do tempo presente". Numa referência atual, mas já clássica pelo seu alcance e consenso, a obra de Marc Bloch L'étrange défaite é acionada para confirmar o mesmo pressuposto ${ }^{19}$.

Mas a história do tempo presente não é apenas um refúgio da nova história política, ou uma dissidência da história contemporânea, ainda que ambas as afirmações sejam procedentes. A concepção de um conhecimento baseado na experiência presente, em constante mutação $e$ aberto às reinterpretações conforme as mudanças previstas, ou não, das sociedades é uma marca identitária da historiografia

\footnotetext{
${ }^{16}$ Interessante notar que Rousso afirma ser esta uma forma que os países da América Latina encontraram para rejeitar a divisão estadunidense baseada na Declaração de Independência dos Estados Unidos da América, em 1776. (Cf. ROUSSO, Sobre a história do tempo presente..., p. 204).

${ }^{17}$ ROUSSO, Henry. La Dernière Catastrophe: L'histoire, le présent, le contemporain. Paris: Gallimard, 2012. O livro foi traduzido para o português pela Editora FGV: A última catástrofe: a história, o presente, o contemporâneo. Trad. Fernando Coelho e Fabrício Coelho. Rio de Janeiro: FGV, 2016.

${ }^{18}$ ROUSSO, Henry. La Dernière Catastrophe..., p. 16.

${ }^{19}$ BLOCH, Marc. L'Étrange Défaite. Paris: Gallimard, 1990. (Escrito em 1940, a primeira edição é de 1946). BÉDARIDA, François. Temps présente et présence de l'histoire. In: IHTP. Écrire l'histoire du temps présent. Paris: CNRS, 1993, p. 393. ROUSSO, Sobre a história do tempo presente..., p. 205.
} 
do século XXI. É, ao mesmo tempo, uma característica tipicamente hermenêutica da historiografia do "tempo presente" por uma dupla via: pela aquiescência à indeterminação da experiência e pela abertura às mudanças de interpretação. "Nós fazemos uma história inacabada. Nós fazemos uma história do inacabado. Nós assumimos o fato de que as análises que vamos produzir sobre o tempo contemporâneo, provavelmente, terão certa duração e que os acontecimentos vindouros podem mudá-las". ${ }^{20}$

Por diversos motivos, mas derivados todos da questão apresentada anteriormente, os historiadores do tempo presente estão mais abertos à hermenêutica, principalmente a ricoeuriana. Em 1978 é fundado o Institut d'histoire du temps présent (IHTP), laboratório do Centre national de la recherche scientifique (CNRS) francês. Alguns dos principais pesquisadores do instituto são exatamente os maiores propagadores da filosofia de Paul Ricoeur entre os historiadores, entre eles Henri Rousso, François Bédarida, François Dosse, Patrick Garcia, Christian Delacroix, Michel Pollak e outros. Pesquisadores de outros períodos e temáticas também compartilham apropriações da filosofia ricoeuriana, mas os ligados ao IHTP concentram a maior parte desses autores. Além da característica "hermenêutica" da história contemporânea, também os debates epistemológicos acerca do conhecimento histórico tornaram-se um grande campo de estudos do instituto, o que faz da filosofia de Ricoeur um componente central.

Henry Rousso reconhece a contribuição teórica de Ricoeur, assim como de Maurice Halbwachs e Hannah Arendt, para a história do tempo presente. A leitura do século XX como trágico e caracterizado mais pela destruição e pelo mal que pelo progresso tecnológico e disseminação da democracia levou os pesquisadores do IHTP a atentarem ao debate acerca do mal tal como desenvolvido por Ricoeur. Vale notar que apesar de Ricoeur ter escrito alguns textos específicos sobre o tema, a questão do mal está presente em toda sua obra, ainda que com abordagens diferentes.

$\mathrm{O}$ mal como algo que de fato existe e que não deveria existir ${ }^{21}$ caracteriza boa parte de todo o seu trabalho. Apresentar o mal como real e inexplicável possibilita mantê-lo como axioma: permite evidenciar a autonomia do real em relação a qualquer estrutura lógica ou ética determinante, na medida em que ele não é desejável e ainda assim é; permite conservar a dupla ação do mal nos sujeitos, seja como culpa, seja como sofrimento, sem fazer do mal uma exclusividade do agressor ou da vítima; permite ainda mostrar que a justiça não se resume apenas a uma simples e falsa equação entre sofrimento e punição, já que no mal existem elementos injustificáveis, como sua própria essência (isso não significa, contudo, que a justiça não se faça pela punição, mas que essa não é capaz, na maioria das vezes, de suprir o sofrimento). Todo o debate desenvolvido por Ricoeur acerca do mal serve para alguns historiadores do contemporâneo - das guerras e catástrofes do século XX como Henry Rousso, enquanto fundamentação filosófica para avaliar teoricamente as possibilidades e limites da narração dos eventos trágicos e, em certa medida, inexplicáveis pelo viés da lógica racionalista. É como um tipo de suporte teórico

\footnotetext{
${ }^{20}$ ROUSSO, Sobre a história do tempo presente..., p. 205-206.

${ }^{21}$ RICOEUR, Paul. O conflito das interpretações: ensaios de hermenêutica. Trad. M. F. Sá Correia. Porto: RÉS, 1988.
} 
(filosófico) necessário para abordar temas que o estrutural parece não dar conta. Henry Rousso comenta a contribuição teórica de Ricoeur acerca do tema do mal da seguinte maneira:

Paul Ricoeur tentou sim compreender o "mal" no sentido filosófico, pois essa era uma das questões que nos colocávamos. Como compreender isso? Como compreender as sequelas que o "mal" pode deixar na consciência das pessoas? Como se comportar com alguém que foi traumatizado, um antigo deportado, por exemplo? Enfim, isso fez parte dos nossos debates teóricos. ${ }^{22}$

Além do efeito do mal nas subjetividades, como Rousso coloca, a hermenêutica do mal de Ricoeur possibilita à história abordar a temática do horror a partir da singularização dos eventos traumáticos, numa linha bastante distinta das abordagens generalizantes que podem, em última instância, transformar o mal em números $e$ estatísticas, gerando o efeito nocivo de desumanização do sofrimento. "O papel ético da compreensão narrativa ao recordar o horror está ligado a uma função específica de individualização: a saber, a necessidade de respeitar a singularidade característica de determinados eventos históricos" ${ }^{23}$. Tendo o genocídio como o evento traumático por excelência, mas sem esquecer Hiroshima, os Gulags, e outros, a historiografia que tem como objeto o século XX recorreu à filosofia ricoeuriana para apresentar a singularidade também por um outro motivo: a reabilitação da função narrativa.

A narrativa de eventos históricos caracterizados pela experiência do mal possibilita uma aproximação mais humana desses eventos, para além da objetividade analítica e pouco compreensiva das estatísticas. A dupla possibilidade de se colocar no lugar dos que sofrem e, ao mesmo tempo, poder refletir acerca de determinado acontecimento somente é possível a partir da narrativa desses eventos. Entre uma objetividade desumanizadora e uma representação plenamente imersiva, ou seja, entre as estatísticas e a ficção histórica com todas as subjetividades que a experiência do terror exige, a historiografia, utilizando-se da narrativa, oferece um caminho misto, tão explicativo quanto compreensivo, e possibilita ao leitor, no ato de refiguração, tanto participar da experiência quanto produzir uma análise.

O historiador que tem como objeto o seu próprio tempo, além de impedido de valer-se do recurso de distanciamento do objeto, precisa lidar ainda com a impossibilidade de conhecer o desfecho da história com a que está trabalhando. Mais uma vez, vários autores ligados à história do tempo presente recorrem à filosofia de Ricoeur para alicerçar seus trabalhos. A ideia de "desfatalização da história" ${ }^{4}$ busca afastar-se da lógica de causa e efeito para a explicação histórica, mantendo a característica de indeterminação da experiência. Em realidade, a expressão "desfatalização da história" foi forjada por Raymond Aron em 1937, mas é de seu uso por Ricoeur, na década de 1990, que a história do tempo presente apropriou-se

${ }^{22}$ ROUSSO, Sobre a história do tempo presente..., p. 210.

${ }^{23}$ KEARNEY, Richard. On the Hermeneutics of Evil. Revue de Métaphysique et de Morale: Paul Ricoeur. N. 2, Abril-Junho de 2006, p. 197-215. p. 208 (tradução nossa).

${ }^{24}$ RICOEUR, Paul. Remarques d'un philosophe. In: IHTP. Écrire l'histoire du temps présent. Paris: CNRS, 1993. 
largamente. Em linhas gerais, a partir dessa proposta os historiadores do tempo presente podem manter em aberto as suas conclusões, de forma a considerar os eventos vindouros como indeterminados.

A desfatalização da história não traz benefícios apenas para os historiadores do tempo presente. A partir do abandono da relação causa-efeito como operador privilegiado da historiografia, evita-se a indesejável lógica retrospectiva que, de forma anacrônica, pode levar o historiador a atribuir uma ação orientada pelos efeitos aos sujeitos de outras épocas. Assim, é possível considerar o presente do passado como tão aberto às ações voluntárias do agir humano $e$, portanto, menos submetido às determinações causais, quanto o da própria história do tempo presente.

\section{História Cultural}

Dentre as várias matrizes da historiografia contemporânea, a história cultural é possivelmente a mais influente, considerando o volume das publicações, a base teórica mobilizada pelos autores desta vertente, a difusão da abordagem cultural em nível mundial e a aceitação ampla por parte do público das obras de história cultural, reflexo de sua capacidade de responder aos questionamentos do presente ou, como coloca Antoine Prost, "[...] a história cultural produz mil novidades e anuncia-se como a história de amanhã, a que convém a um tempo mais desencantado e mais narcísico" 25 .

O cânone da história cultural contemporânea é a obra coletiva dirigida por JeanPierre Rioux e Jean-François Sirinelli Para uma história cultura ${ }^{26}$. Lançada na França em 1997 e traduzido rapidamente para vários idiomas - para português já em 1998, pela editora lusitana Estampa - a obra tem pretensões nada modestas, o que fica bastante claro na introdução à obra redigida por Rioux: busca articular teórica, metodológica e tematicamente todos os desdobramentos recentes da história cultural, a partir da contribuição de vinte e cinco autores centrais dessa corrente historiográfica. Além disso, tem uma forte propensão à afirmação programática. $\mathrm{O}$ livro é fruto dos debates realizados pelos autores em seminários dirigidos pelos organizadores da obra desde 1989. Deve-se notar que estes seminários tiveram início, não coincidentemente, no IHTP. A questão do presente como período privilegiado da historiografia do final do século XX e do início do século XXI é patente não apenas na abordagem que tem esse recorte como sua característica básica - a história do tempo

${ }^{25}$ PROST, Antoine. Social e cultural indissociavelmente. In: RIOUX, Jean-Pierre; SIRINELLI, JeanFrançois (dirs). Para uma história cultural. Trad. Ana Moura. Lisboa: Estampa, 1998, p. 123-137, p. 123.

${ }^{26}$ RIOUX, Jean-Pierre; SIRINELLI, Jean-François (dirs). Para uma história cultural. Trad. Ana Moura. Lisboa: Estampa, 1998. (1 ed. em francês: Paris: Seuil, 1997). No mesmo ano, essa dupla de historiadores dirigiu também a coleção Histoire culturelle de la France, em quatro volumes. Outras publicações de peso se seguiram na década de 2000, com destaque para: Les enjeux de l'histoire culturelle e Histoire culturelle: um "tournant mondial" dans l'historiographie de Philippe Poirrier (na segunda como diretor); Dictionnaire d'histoire culturelle de la France contemporaine, de Delporte, Mollier e Sirinelli; e Histoire culturelle de la France de la Belle Époque à nos jours, de Goetschel e Loyer. Esta não pretende ser uma lista exaustiva, mas apenas referenciar as principais publicações sobre o tema no período. Todas elas seguem os direcionamentos propostos em Para uma história cultural. 
presente - mas também na história política, cultural e social. Quanto à obra Para uma história cultural, trata-se de uma afirmação não apenas do cultural, mas do cultural como elemento distintivo do contemporâneo.

Dentre as preocupações dos autores que contribuíram para a obra está a necessidade de relacionar a história cultural à história social. O capítulo de autoria de Antoine Prost está todo voltado justamente a este tema. Rioux resume bem a questão: "[...] toda a história, por definição, é social e sonha ser total" ${ }^{27}$. O que está em jogo é evitar que a história cultural possa dar a impressão de autonomia relativa ao social, o que a aproximaria da acepção estética da cultura e dos objetos de arte. Após décadas de domínio das abordagens econômica e social, ambas alicerces da estratigrafia, tanto marxista quanto annaliste, a história cultural precisou afirmar seu componente coletivo para evitar ser subestimada frente às infraestruturas. De fato, para além de uma necessidade de legitimação, a história cultural dialoga facilmente com a história social, mas sem partir de grupos sociais já previamente aceitos e constituídos.

Um determinado tipo de história social, como a que se encontra no período em que as chamadas "monografias regionais", no estilo laboussiano, estiveram em alta (principalmente nas décadas de 1950 e 1960), pouco questionava a formação dos grupos sociais, mas antes apenas o recebiam como já definidos: camponeses, proprietários, proletariado, burgueses, nobres, entre outros modelos de classe ou grupos. Contra essas "essências" sociais, a história cultural busca definir os grupos identitários para além das determinações do ofício e da posse, ou não, dos meios de produção, ao ponto de afirmar, como Antoine Prost, que "o grupo só existe na medida em que existe voz e representação, quer dizer cultura" 28 . Ao diminuir a importância, por exemplo, das separações entre cultura popular e cultura erudita, os historiadores da cultura buscam apresentar os laços e confrontos sociais partindo da fluidez dos elementos culturais, outra forma de "desfatalizar" (noção cara a Ricoeur) as formações sociais. Pelo menos é essa a acusação dos historiadores da cultura quanto à história social: pode-se afirmar que os historiadores do social aceitavam assim tão facilmente as "classes" predefinidas, ou seria esta uma forma de desabonar o modelo que a abordagem cultural pretende substituir? Possivelmente ambas as afirmações são parcialmente verdadeiras.

Por vezes, os historiadores da história cultural dão continuidade a perspectivas abertas pela história social ou das mentalidades, contudo, destacando sempre a inovação trazida pela perspectiva cultural. Exemplo disso é a multiplicação de publicações que tratam a "invenção" cultural de elementos "naturais". Na esteira de Michel de Certeau, tornou-se popular a utilização da palavra "invenção" para humanizar processos ou objetos não artificiais - no sentido de que não são necessariamente produzidos intencionalmente pelos homens. Portanto, a invenção de algum período, como, por exemplo, o século XIX, ou a invenção dos corpos, da paisagem, das catástrofes, enfim, todo um trabalho sobre a historicidade das representações é reivindicado pela história cultural.

\footnotetext{
${ }^{27}$ RIOUX, Jean-Pierre. Introdução: um domínio e um olhar. In: ; SIRINELLI, Jean-François (dirs). Para uma história cultural. Trad. Ana Moura. Lisboa: Estampa, 1998, p. 11-22, p. 13.

${ }^{28}$ PROST, Antoine. Social e cultural indissociavelmente..., p. 129.
} 
Os dois volumes da obra $A$ Invenção do Cotidiano $^{29}$ repercutiram notadamente entre a comunidade de historiadores ligados à História Cultural. $\mathrm{O}$ estabelecimento de novas fontes, tal como proposto por Certeau, permitiu à História Cultural uma significativa ampliação de temas e abordagens. Anos antes da publicação de $A$ Invenção do Cotidiano, porém, na ocasião da sistematização da operação historiográfica, Certeau já havia definido este novo estatuto das fontes, acerca do qual os historiadores do cultural se apoiaram de forma especialmente profícua.

A operação historiográfica, grosso modo, consiste em três premissas básicas: as produções dos historiadores estão submetidas a um lugar de produção; são constituídas por práticas "científicas" e, por fim, são fixadas por meio de uma escrita. Apoiando-se no que chamou de "um despertar epistemológico" de fins dos anos de 1960, Certeau buscou apresentar quais são os elementos constituintes da prática historiográfica que não estão expressos no discurso do historiador.

O segundo elemento da operação historiográfica é definido por uma prática, o "fazer história". Essa prática comporta uma série de elementos; o primeiro deles é a forma como o historiador percebe cada sociedade historicamente de acordo com suas técnicas. Sempre pautamos nossa relação com o tempo a partir das técnicas disponíveis; é assim, por exemplo, que se renovam os objetos da historiografia. A articulação natureza-cultura, então, é produto das técnicas disponíveis em cada época:

Uma obra 'histórica' participa do movimento através do qual uma sociedade modificou sua relação com a natureza, transformando o natural em utilitário (por exemplo, a floresta em exploração), ou em estético (por exemplo, a montanha em paisagem), ou fazendo uma instituição social passar de um estatuto para outro (por exemplo, a igreja convertida em museu). ${ }^{30}$

Essa prática se efetua quando o historiador estabelece suas fontes. Em realidade, trata-se do deslocamento de materiais produzidos com fins práticos transformados (i.e., criados) pelo historiador para fazer história. Esse estabelecimento das fontes a partir do deslocamento - tanto material quanto do sentido - é que garante ao historiador um corpo de materiais manejáveis. A história cultural se nutriu dessa abertura ao estudo do mundo material pelo viés da cultura, em contraparte ao marxismo, como possibilidade de renovação dos estudos culturais. Certamente este não foi o único aporte de Certeau para a história cultural, mas constitui a base teórica de suas contribuições.

Outro autor bastante importante como referência teórica para a história cultural foi Michel Foucault. Entre os autores que constituem o que Certeau chamou de "despertar epistemológico" de fins dos anos 1960, Foucault desempenha uma função

${ }^{29}$ CERTEAU, Michel de. A invenção do cotidiano: 1. Artes de fazer. Nova edição, estabelecida e apresentada por Luce Giard. Trad. Ephraim Ferreira Alves. 19 ed. Petrópolis: Vozes, 2012.; invenção do cotidiano: 2. Morar, cozinhar. Trad. Ephraim F. Alves e Lúcia Endlich Orth. 11 ed. Petrópolis: Vozes, 2012.

${ }^{30}$ CERTEAU, Michel de. A escrita da história. Trad. Maria de Lourdes Menezes. 2 ed. Rio de Janeiro: Forense Universitária, 2006, p. 79-80. 
singular, na medida em que dialoga com a tradição dos Annales e empreende uma renovação da prática documental, acompanhada de uma sistematização epistemológica do processo de atualização da historiografia pós-segunda geração dos Annales. Certamente o trabalho de Foucault, A Arqueologia do Saber ${ }^{31}$, não é historiográfico. Todavia, o livro teve uma repercussão decisiva entre os historiadores da chamada terceira geração dos Annales. Em certa medida, a filosofia de Foucault caminhou paralelamente ao trabalho desenvolvido pelos Annales pós-Braudel. As descontinuidades, as relações de poder heterogêneas não necessariamente ligadas ao Estado, as multiplicidades, o trabalho sobre as diferenças; enfim, toda uma sistematização do processo de superação das totalidades características das epistemologias dominantes da historiografia do século XX (em especial do marxismo e do modelo da primeira e segunda geração dos Annales), é compilada por Foucault em A Arqueologia do Sabere em outras publicações, de forma que os autores ligados à Nova História, em especial à sua vertente cultural, se apropriam de suas reflexões como sustentação teórica para a mutação da historiografia em curso. As diversas referências a sua obra, por parte de historiadores como Jacques Le Goff, Roger Chartier, Paul Veyne e muitos outros, evidenciam o que significou a filosofia foucaultiana para a historiografia francesa.

O pluralismo característico da historiografia contemporânea é especialmente influente no campo história cultural, ao ponto de até mesmo o "conceito" de cultura ser substituído por um inventário de noções mais plurais e adequadas à multiplicidade de vias de acesso ao cultural. Como coloca Rioux,

O novo rumor do mundo reabriu em primeiro lugar e de repente à investigação da história todas as acepções, universais, sociais e individuais, da palavra "cultura"; a mais ontológica, que distingue a existência humana do estado natural, com sinais distintos e marcas simbólicas, sistemas de funções e práticas, apropriação coletiva e condições de civilização; a mais antropológica, que faz da cultura um conjunto de hábitos e de representações mentais próprios de um dado grupo num dado momento, com o seu cortejo móvel de costumes e crenças, de leis e de técnicas, de artes e linguagens, de pensamento e mediações; finalmente a mais "clássica" e tão "esclarecida", que reconduz a cultura ao saber, um processo no decorrer do qual o indivíduo pensante estimula as faculdades do espírito. ${ }^{32}$

Vale notar que, segundo o autor da citação anterior, a abertura da história cultural é nada menos que efeito de um "novo rumor do mundo". O domínio da história cultural, nesse sentido, é tão amplo quanto às noções que a define. Compreende o estudo das instituições e políticas públicas, dos suportes materiais, das tradições $e$

${ }^{31}$ FOUCAULT, Michel. A arqueologia do saber. Trad. Luiz Felipe Baeta Neves. 7 ed. Rio de Janeiro: Forense Universitária, 2010.

${ }^{32}$ RIOUX, Jean-Pierre. Introdução: um domínio e um olhar..., p. 17. 
mediações culturais, das práticas de apropriação e difusão, das identidades e modos de sociabilidade, do universo discursivo, além, é claro, dos próprios símbolos culturais, ou "o mundo como representação", conforme Chartier ${ }^{33}$.

As noções de "representações" e "práticas" passaram a ser centrais para a história cultural, na medida em que permitem abordar os aspectos simbólicos da cultura, assim como a experiência cultural enquanto ação no mundo. Assim, não apenas os "sentidos" das obras são discutidos, mas também as práticas envolvendo elementos culturais. Roger Chartier e Michel de Certeau foram os historiadores que mais se dedicaram a elaborar conceitualmente essas noções, depois de tê-las aplicado, em especial, em seus trabalhos acerca da história da leitura e da historicidade das práticas do cotidiano.

As práticas analisadas pela história cultural são bastante mais amplas que simplesmente o ato de escrever ou ler, ainda que estas sejam, sem dúvida, práticas culturais decisivas. Tanto as formas de ensino e aprendizagem quanto a adoção de determinados comportamentos são práticas culturais. Os hábitos de higiene, a relação com os estrangeiros, as atitudes diante da morte, enfim, todo um conjunto de elementos de vínculo social e cultural que implica alguma ação é considerado como prática cultural. Podemos notar, nesse sentido, a tamanha dívida que o estudo das práticas culturais tem para com a sociologia de Norbert Elias.

As representações são tão dependentes quanto determinantes em relação às práticas. É a partir de uma visão de mundo específica acerca de determinado tema que os grupos sociais estabelecem concepções e posturas compartilhadas sobre a experiência. As representações são partes constituintes das práticas: são símbolos de cultura que, junto com as práticas, formam a totalidade das visões e ações sobre o mundo. A afluência da representação na prática cultural é articulada de forma exemplar por Ricoeur. Em sua obra Percurso do Reconhecimento, o autor afirma que

Esse vínculo entre representações e práticas sociais se expressa no papel de mediação simbólica que as primeiras exercem quando as segundas têm um conteúdo determinado, a saber, a instauração do vínculo social e das modalidades de identidade que estão ligadas a ele. As representações não são, pois, ideias flutuantes que se movem em um espaço autônomo, mas, como acabamos de dizer, mediações simbólicas que contribuem para a instauração do vínculo social; elas simbolizam identidades que conferem uma configuração determinada a esses vínculos sociais em instauração. ${ }^{34}$

A barreira que divide as práticas das representações é, portanto, muito efêmera. Os historiadores ligados à perspectiva da história cultural não poderiam definir as diferenças entre práticas e representações como se fazia, ou se caricaturava, com as

${ }^{33}$ CHARTIER, Roger. Le monde comme representation. Annales. Économies, Sociétés, Civilisations. 44 e année, N. 6, 1989, p. 1505-1520.

${ }^{34}$ RICOEUR, Paul. Percurso do reconhecimento. Trad. Nicolás Nyimi Campanário. São Paulo: Loyola, 2006, p. 149. 
infra e superestruturas. A crítica em relação às predefinições da história social é a condição negativa da nova história cultural. Não encontraremos nos historiadores da cultura uma oposição entre práticas ou representações, mas sempre a forma de conjunção aditiva. A indissociabilidade entre práticas e representações é da mesma ordem que se estabelece entre o cultural e o social. $\mathrm{O}$ universo da linguagem exemplifica bem este pluralismo.

A questão dos discursos e do universo simbólico da linguagem é especialmente relevante para a história cultural. Parte-se do pressuposto de que comunicar já é produzir cultura. Até mesmo uma definição de sociocultural mais ampla é liberada pela centralidade dos discursos: os vínculos sociais se dão por meio dos discursos e, assim, a história cultural e a história social estão unidas pelo elemento que garante tanto a constituição quanto a reprodução sociais. Todo um conjunto de objetos de estudo ligado aos discursos está no centro das pesquisas culturais, tais como as práticas de leitura, a história dos livros e impressos, assim como das línguas propriamente, como no estudo da passagem efetuada na Idade Média Central entre a primazia do latim e o avanço das produções em línguas vernáculas. A partir da leitura e da escrita, a história cultural é capaz de vincular três elementos constituintes da historicidade da linguagem: os objetos culturais, a produção dos discursos e os usos sociais destes.

Ligada também aos aspectos discursivos, mas com outra abordagem, temos como interlocutora da história cultural a história dos conceitos. O trabalho de elaborar os desenvolvimentos históricos que constituem os alicerces da utilização que se faz dos conceitos e da linguagem como sistema simbólico é uma das possibilidades trazidas à história a partir da centralidade dos discursos. Aqui, história social da linguagem, história cultural dos discursos e das obras e história dos conceitos e dos sistemas de linguagem interagem para a constituição de um conglomerado de trabalhos culturais que buscam na linguagem o fio condutor da historicidade.

\section{Nova História Social}

Das diversas renovações historiográficas que tiveram lugar na passagem do século $\mathrm{XX}$ para o século XXI, a da história social é a mais peculiar. Isso porque se trata de buscar dar uma nova roupagem à perspectiva historiográfica dominante na historiografia francesa ao longo de quase todo o século XX. Num momento em que diversas correntes historiográficas alegam um afastamento em relação à historiografia produzida sob a égide do estruturalismo, da seriação e da longa duração, a história social está numa posição de "renovação do triunfante". As questões que orientaram a história social ao longo do século XX são colocadas em xeque e o corolário disso é a dúvida na capacidade de representação da perspectiva que mais sucesso obteve naqueles moldes.

Todavia, a força do domínio do social na história é tamanha que argumentos de autoridade dificilmente questionáveis são acionados, como o de que "toda história é necessariamente social", ou o de que "a história é uma ciência social", ou ainda que "outras áreas da pesquisa histórica, como a cultural, econômica ou política são nada mais que diferentes expressões do social". Não faz parte de nossos objetivos, todavia, avaliar o estatuto da história social, mas sim como os historiadores defensores dessa 
perspectiva histórica buscaram reformular seu ofício frente a todas as viradas que caracterizaram as últimas décadas.

A obra que melhor caracteriza essa busca por uma atualização da história social é Les formes de l'expérience, com o sugestivo subtítulo Une autre histoire sociale $e^{35}$. Publicada em 1994, este conjunto de estudos organizado por Bernard Lepetit é fruto de discussões realizadas entre os pesquisadores do Centre de recherches historiques da École de hautes études em sciences sociales no final do ano de 1993. Com a participação de historiadores como o próprio Lepetit, Alain Boureau, Jacques Revel, Jean-Yves Grenier, André Burguière, entre outros, a obra é uma tentativa de organizar as tendências da história social conforme as novas orientações da pesquisa historiográfica que caracterizam o fim do século.

A marca dos Annales é evidente na obra: em primeiro lugar, ela é publicada na coleção L'Évolution de l'Humanité, coleção fundada na década de 1920 por Henri Berr e na qual foram publicadas as principais obras dos historiadores dos Annales, na ocasião da publicação de Les formes de l'expérience, Bernard Lepetit era o diretor da coleção. Outro ponto bastante característico da influência dos Annales é a orientação prática dos textos. Em geral, todos os capítulos que compõem o livro têm a característica de "práticas" de história social, conforme os diferentes objetos. Apesar de não se tratar de uma obra publicada sob a chancela dos Annales, a maioria dos autores que está no livro já ocupou cargos de direção, redação ou edição da revista. Em geral, podemos afirmar que após um primeiro momento de suspeita quanto às direções que a historiografia tomou no final do século, os Annales percebem a inevitabilidade dos novos cursos da história e partem para um trabalho de apropriação crítica, ou melhor, de apropriação seletiva de questões ligadas à narrativa, à volta dos acontecimentos e atores históricos, ao trabalho interpretativo em concorrência com as explicações estatísticas, entre outros.

Conforme Bernard Lepetit, a reorganização da história social passa por duas questões centrais, que se desdobram em problemas derivados. A primeira delas é a superação das determinações imperialistas da produção nas ciências sociais. $O$ pluralismo interpretativo é aqui acionado como via de superação dos modelos de explicação dominantes ao longo do século XX. No que toca em especial a história social, é o predomínio do estruturalismo e das explicações baseadas nas quantificações que Lepetit declara terminado. Isso não implica, contudo, negligenciar os avanços obtidos ao longo de todo o período caracterizado pelas quantificações. $\mathrm{O}$ texto de Jean-Yves Grenier "Expliquer et comprendre: la construction du temps de l'histoire économique" ${ }^{36}$, publicado na obra Les formes de l'expérience, busca justamente articular as questões da história serial com as novas orientações da produção historiográfica. Assim, a herança da história social é mantida e expandida pela apropriação dos princípios hermenêuticos de interpretação compreensiva.

E aqui a questão que atravessa toda a obra de Paul Ricoeur Tempo e Narrativa é essencial. A constituição de uma dialética entre explicação e compreensão conduz o pensamento ricoeuriano ao longo das mais de mil páginas da obra. Superar as

${ }^{35}$ LEPETIT, Bernard (dir). Les formes de l'expérience: Une autre histoire sociale. Paris: Albin Michel, 1994.

${ }^{36}$ GRENIER, Jean-Yves. Expliquer et comprendre. La construction du temps de l'histoire économique. In: LEPETIT, Bernard. Les formes de l'expérience: une autre histoire sociale. Paris: Albin Michel, 1995. 
determinações metodológico-explicativas da história ciência não significa ignorá-las, mas antes articulá-las à dimensão compreensiva. Para o trabalho do historiador, o esforço ricoeuriano no sentido de confirmar a tese de que explicar mais é compreender melhor oferece um caminho seguro para toda a tarefa de renovação da historiografia, tarefa indispensável no momento de incertezas pelo qual passam as ciências sociais.

Assim, a cientificidade da história, seja ela positivista, estrutural ou serial, articulase e enriquece-se com o olhar mais humanizado, compreensivo, que se dedica aos sujeitos, ações situadas $e$ interpretações em geral. Dialetizar explicação $e$ compreensão é um meio de assegurar o desenvolvimento da historiografia contemporânea sem a necessidade das grandes quebras epistemológicas, que em geral levam os novos grupos a ironizar e caricaturar escolas históricas precedentes, implicando o prejuízo de não reconhecer as virtudes da pluralidade das perspectivas heterogenias. Os historiadores podem obter um duplo ganho desta lição ricoeuriana: o aumento da capacidade explicativa-compressiva pela soma de perspectivas e uma relativa pacificação epistemológica da disciplina.

Retomando os debates do historiador da virada crítica, a segunda questão destacada por Lepetit é a do duplo estatuto da historiografia, que se constitui enquanto uma apresentação do referente passado, por meio do agenciamento linguístico, mas não se resume, de um lado, a uma duplicação do real, e de outro, a um mero jogo linguístico. É um misto de discursos, técnicas, procedimentos críticos e interpretação que constitui a prática característica do trabalho historiográfico.

Dessas duas questões iniciais, Lepetit define um novo programa para a história social:

Propõe-se primeiramente reordenar a hierarquia de interesses da disciplina colocando como problema prioritário a questão das identidades e das conexões sociais. A uma história das mentalidades muito estritamente entendida, trata-se de lembrar que os homens estão não somente no mundo, mas que eles estão entre eles, e que não se pode considerar que eles vivem em um universo de representações indiferentes às situações em que se encontram ativos. ${ }^{37}$

Lepetit continua a apresentação do programa proposto colocando em pauta outros deslocamentos que se fazem necessários. A quantificação que caracterizou a história social é questionada a partir da observação individualizada dos objetos e dos atores sociais. É ressaltada a necessidade de problematizar as categorias sociais no sentido de não mais aplicá-las verticalmente aos indivíduos, mas de mostrar a constituição destas por meio dos usos e práticas sociais. As identidades e conexões sociais devem então passar a serem vistas não mais como naturais $e$ anteriores aos sujeitos, mas criadas a partir da experiência destes. Em decorrência destes deslocamentos, Lepetit indica ainda que os modelos cronológicos de superposição de estratos temporais no estilo braudeliano, o encadeamento de estruturas temporais previamente

37 LEPETIT, Bernard. Histoire des pratiques, pratique de l'histoire. In: l'expérience: une autre histoire sociale. Paris: Albin Michel, 1995b, p. 9-22, p. 13 (tradução nossa). 
determinadas, tais como estrutura e conjuntura, além das sincronias imobilizadas de algumas leituras da história das mentalidades devem ser reexaminadas, tendo em vista o deslocamento da atenção dos grandes modelos pré-fabricados em favor das ações, situações e atores situados. E o alcance desta nova caracterização dos regimes temporais não deve se resumir à disciplina história: é necessário estendê-la a todas as ciências sociais. Em linhas gerais, o programa proposto pelos autores signatários de Les formes de l'expérience busca substituir as análises a partir de modelos enrijecidos pela abordagem localizada da experiência em suas variações e indeterminações.

Observa-se claramente, nesse sentido, uma orientação pragmática nas propostas de renovação da história social. Aqui o deslocamento realizado em favor dos acontecimentos $e$ atores sociais, da teoria da ação, da identidade e da ação situada remete abertamente às vias hermenêuticas de compreensão dos sujeitos históricos. A abertura à indeterminação da experiência deve espelhar-se na historiografia tal qual ela se dá na prática, em contraposição às determinações modelares: "A sociedade não dispõe, para organizar suas estruturas do momento ou regular suas dinâmicas, de nenhum ponto fixo exterior e que lhe é transcendente. [...] Ela é, para a análise, por sua vez objeto e princípio de explicação." 38

O maior desafio dos historiadores empenhados em renovar a história social é o de equilibrar os avanços obtidos a partir da quantificação estatística, seriações $e$ explicações pautadas pelas flutuações, demográficas ou econômicas, por exemplo, com a tendência à compreensão dos acontecimentos e atores situados pela via hermenêutica. Jean-Yves apresenta bem esse dilema em seu já citado texto "Expliquer et comprendre: la construction du temps de l'histoire économique" ${ }^{39}$. Segundo ele, mesmo ao considerar os dados estatísticos, a parcela de interpretação é até mesmo maior que a objetividade numérica. Isso porque ao lidar com os números, duas tarefas distintas devem operar conjuntamente: uma primeira estritamente ligada aos cálculos que respondem apenas à lógica matemática, e a segunda que diz respeito à interpretação dos resultados obtidos na primeira etapa. A objetividade dos dados obtidos a partir dos cálculos pode dar a falsa impressão de uma objetividade equivalente na interpretação desses dados; todavia, na prática, pode surtir um efeito contrário, na medida em que é a compreensão que atribui sentido aos resultados do dispositivo quantitativo, que de outra forma seriam apenas números sem referentes reais. Segundo Grenier, portanto, a noção de interpretação é central, mesmo se tratando de dados matemático-estatísticos. Essa conclusão pode parecer um truísmo, mas ao considerarmos algumas tendências das ciências sociais que consideram os números como fins e não como meios para se atingir a humanidade do passado, o alerta torna-se necessário.

Mas não só de readequações de conquistas anteriores é feita a renovação da história social. Uma característica notável desse trabalho de reestruturação é a abertura às contribuições à área advindas de fora da França. Até meados do século $\mathrm{XX}$, a história social francesa se desenvolvia conforme as alianças que estabelecia entre as diferentes ciências sociais no meio francês. Todavia, ao longo das últimas

\footnotetext{
${ }^{38}$ LEPETIT, Bernard. Histoire des pratiques, pratique de l'histoire..., p. 14 (tradução nossa).

${ }^{39}$ GRENIER, Jean-Yves. Expliquer et comprendre. La construction du temps de l'histoire économique. In: LEPETIT, Bernard. Les formes de l'expérience: une autre histoire sociale. Paris: Albin Michel, 1995.
} 
décadas do século XX e início do XXI, as transformações da historiografia fora da França passaram a fazer parte dos debates da história social. Alguns historiadores franceses, inclusive, tornaram-se porta-vozes dos trabalhos historiográficos produzidos em outras partes do mundo. Jacques Revel, por exemplo, introduz de forma bastante eficaz a micro-história italiana, inclusive em meios pouco propensos à aceitação de análises pautadas pela atomização dos objetos. A ampla recepção da obra Jeux d'échelles: la micro-analyse à l'expérience ${ }^{40}$ é prova desse movimento. Outro historiador que desempenhou papel parecido foi François Hartog. Suas diversas publicações acerca da obra de Reinhart Koselleck foram basilares para acelerar o processo de recepção do historiador alemão. Ao longo da década de 1990, a obra de Koselleck já era conhecida entre os intelectuais de praticamente todo o mundo. Ainda que outras vias de acesso a seu trabalho tenham desempenhado papel importante, os debates apresentados por Paul Ricoeur e François Hartog foram, para tanto, essenciais.

Uma aproximação não tão recente, contudo não menos importante, diz respeito à história social inglesa. A leitura das obras de Edward Palmer Thompson e seus seguidores não é uma novidade. A história das classes operárias fez escola em todo o mundo devido sua capacidade de representar as particularidades da classe trabalhadora que, de certa forma, desperta vínculos identitários supranacionais. Mas foi a questão da historicização das categorias sociais o grande diferencial para a renovação da história social. Na obra de Thompson, o trabalho com as categorias sociais é diferente da aplicação de conjuntos sociais definidos por função ou acúmulo de riqueza. Não se trata, portanto, de etiquetar os sujeitos com posições previamente definidas. Segundo o historiador inglês, as classes sociais não são coisas, mas relações históricas de produção mutáveis, e os sujeitos não se submetem a elas, mas antes as constituem conforme sua participação ativa na formação de vínculos sociais. Os operários, por exemplo, atualizam uma relação histórica e agem sobre ela. Além disso, não apenas as classes dependem da ação ativa dos atores sociais como também as análises destas devem estar pautadas pela representação coletiva que aquela sociedade, na qual se inserem, faz dos grupos sociais. Assim, tanto os perigos da aplicação de predefinições rígidas aos grupos sociais sempre em mutação quanto o problema da imposição retrospectiva de estruturas explicativas são evitados. A história social em processo de atualização se apropriou da perspectiva de construção ativa das categorias.

A história econômica, ainda que com menor fôlego, também aderiu ao trabalho de readequação das categorias sociais.

Descontruímos, por assim dizer, os grandes agregados que são o capitalismo, a burguesia, a classe trabalhadora, o Estado, para redescobrirmos que é preciso interessar-nos

${ }^{40}$ REVEL, Jacques (dir.). Jeux d'échelles: la micro-analyse à l'expérience. Paris : Gallimard-Le Seuil, 1996. 
pelos homens, para reconstruirmos melhor, em seguida, conjuntos de contornos mais permeáveis e mutáveis ${ }^{41}$.

O trabalho reorganização da história social passa pela manutenção da primazia do social, mas não mais remetendo à segurança das categorias previamente aceitas $e$ seguras posto que consideradas 'universais' e imutáveis, mas partindo da posição diametralmente oposta: a partir da fluidez da constituição social, e sendo o próprio social tanto a referência quanto o motor de reprodução da história social, esta se apresenta como independente de qualquer elemento externo que a determine. A grande frente de batalha da nova história social é o antideterminismo, o antiestruturalismo. Estes historiadores estão essencialmente preocupados em ressaltar a liberdade, seja dos objetos históricos em sua constituição, seja historiográfica e metodológica. Evita-se todo o previamente determinado, no que tange às configurações sociais dos objetos de análise e quanto aos procedimentos historiográficos de analisá-los.

\section{Elementos comuns das quatro áreas}

A historiografia que nasce da crise passa pela reabilitação de perspectivas historiográficas relativamente deixadas de lado pela corrente dominante ao longo do século XX, com ênfase na adequação aos novos tempos. Alguns novos elementos como temáticas, abordagens e referenciais teóricos são criados. Após um momento que François Dosse caracterizou como "a história em migalhas", a "reconstrução" da disciplina se dá menos a partir de uma revitalização das velhas hierarquias temáticas e metodológicas que caracterizaram a instituição histórica ao longo do século passado, e mais pelo caminho da pluralidade.

Encontramos alguns elementos em comum nestes trabalhos de reformulação das pesquisas históricas. Entre eles, três merecem destaque: a reabilitação dos sujeitos e personagens da história; o papel dos acontecimentos e da ação situada; e a relativização das categorias explicativas. Entre o primeiro (papel dos atores históricos) e o segundo (foco na ação) cria-se uma tensão que parece ainda não ter sido objeto de análise entre os historiadores contemporâneos. É a ação situada ou o personagem histórico que está no centro das produções historiográficas atuais? Ricoeur, ao discutir a filosofia de Aristóteles, apresenta a questão: "É em ética [...] que o sujeito precede a ação na ordem das qualidades morais. Em poética, a composição da ação pelo poeta rege a qualidade ética dos caracteres" ${ }^{2}$. Transpondo o questionamento aristotélico do par mímesis-mŷthos para os desdobramentos da historiografia contemporânea, podese avaliar em que medida a ação e o sujeito desempenham funções distintas $e$ complementares na configuração da narrativa histórica no pós-estruturalismo. Considerando a composição narrativa como produto do trabalho historiográfico, poder-se-ia afirmar a primazia das ações sobre os sujeitos. Todavia, para a história

${ }^{41}$ DAVIET, 2000 apud DELACROIX, Christian; DOSSE, François; GARCIA, Patrick. As correntes históricas na França: séculos XIX e XX. Trad. Roberto Ferreira Leal. Rio de Janeiro: FGV, 2012, p. 335.

${ }^{42}$ RICOEUR, Paul. Tempo e narrativa: Volume 1. A intriga e a narrativa histórica. Trad. Claudia Berliner. São Paulo: WMF Martins Fontes, 2010, p. 68. 
social, econômica e cultural, a ação, de fato, prevalece, enquanto para a história oral, história do tempo presente e algumas correntes da micro-história, o sujeito é o protagonista.

Mas é o terceiro dos elementos comuns listados anteriormente o que mais chama a atenção. O trabalho contra as categorias pré-determinadas, que se convencionou chamar de "reificação das categorias", é compartilhado pelas mais diversas correntes historiográficas contemporâneas, mas tem um papel primordial em duas: na história social e na história cultural. Contudo, acreditamos que existe uma diferença fundamental entre elas.

Tanto a história cultural quanto a social buscam, em seus esforços de reorganização, desvencilhar-se das estruturas pré-interpretativas sem, contudo, abdicar dos avanços obtidos por elas. As vias para a superação das determinações sociais, contudo, são diferentes. A história cultural é, em geral, sobremaneira influenciada pela sociologia de Pierre Bourdieu e de Norbert Elias, assim como pela obra de Michel de Certeau, enquanto a história social busca remodelar-se a partir da pluralidade dos mundos da ação. Paul Ricoeur é aqui central para o projeto de renovação da história social, como evidencia Bernard Lepetit em seu texto "Le présent de l'histoire" ${ }^{43}$. Essa diferença não é a única que se observa entre o movimento social e cultural, mas representa bem as sutis separações entre elas, ainda que seja amplamente aceita a sobredeterminação sócio-cultural tal como exposta por Antoine Prost em seu célebre texto "Social e cultural indissociavelmente". Dessa forma, a história cultural segue no sentido do questionamento das categorias, contudo, sem refutar formas mais sutis de predeterminações, como as que se apresentam no modelo bourdieusiano, adotado pela história cultural, por meio dos conceitos centrais de habitus e campo.

Entre, por um lado, a virtualidade estruturalista, na qual os indivíduos e grupos sociais estão submetidos invariável $e$ inconscientemente às determinações estruturais e, por outro, o conceito de habitus tal como desenvolvido por Bourdieu, há uma mudança de escala, mas não de subordinação. Em ambos os casos são as forças externas, virtuais e reguladoras que conduzem a vida. Contudo, enquanto o estruturalismo privilegia "lugares vazios" ou posições simbólicas afetadas pelas determinações estruturais, que podem ser - ou não - atualizadas em sujeitos, o habitus de Boudieu faz já uma pequena concessão ao admitir que são os sujeitos que incorporam o habitus. Reconhecer o papel dos sujeitos não é, todavia, libertá-los do jugo da estrutura, mas atomizar a imposição do poder simbólico. Vale ressaltar que uma abordagem na qual o sujeito está plenamente livre e apto a realizar qualquer pulsão é tão prejudicial quanto negar ao sujeito qualquer possibilidade de ação no mundo. A medida do equilíbrio deve ser dada pelo objeto em questão. É o próprio referente, e não uma determinação metodológica prévia, que indica o grau de determinação e de liberdade dos sujeitos, instituições ou sociedades abordadas pelo historiador.

Para a nova história social, a experiência é a referência $e$ o motor da história, $e$ esta é sempre singular. A explicação é dada pelo desenrolar mesmo dos fenômenos e

${ }^{43}$ LEPETIT, Bernanrd. Le présent de l'histoire. In: histoire sociale. Paris: Albin Michel, 1995.

(dir). Les formes de l'expérience: Une autre 
não por uma estrutura analítica previamente determinada. Os textos que constituem Les formes de l'expérience dão testemunho desse movimento. Isso não significa não questionar as fontes: parte-se de perguntas, mas a força das hipóteses é substituída pela abertura à indeterminação advinda da observação da experiência.

Essa nova postura da história social caracteriza uma forma de levar ao extremo a pragmática e a singularidade das formações sociais. É assim primordial levar em consideração a compreensão dos sujeitos históricos que constituem cada sociedade como a medida para o estabelecimento da classificação social deles mesmos. Parte-se do pressuposto de que categorias sociais "atemporais" não podem explicar todas as formações possíveis. Pelo contrário, além de historicizar o objeto de trabalho, deve-se historicizar também a lente pela qual o historiador vê seu objeto. Isso não caracteriza, contudo, uma tentativa de voltar às propostas do romantismo, especialmente a de poder transferir-se para uma outra mente, mas sim de auferir, a partir das fontes, como os contemporâneos estratificavam sua própria sociedade e basear a análise nesse indicador.

Paul Ricoeur notou esse deslocamento realizado pela história social. Mas ele não apenas tratou essa questão como um simples objeto de suas teses filosóficas como ofereceu aos historiadores uma base conceitual viável, mais pautada pela ontologia da condição histórica que pela epistemologia, para esta proposta que corre o risco de ser acusada de pouco científica por desviar-se, mesmo que não completamente, dos padrões metodológicos, das categorias e dos modelos explicativos aceitos da história social edificada sobre os pilares da historiografia do século XX. Para Ricoeur,

O historiador não tem apenas como contraponto mortos, para os quais ele constrói um túmulo escriturário; ele não se dedica apenas a ressuscitar viventes de outrora, que não existem mais, mas que existiram; ele se dedica a reapresentar ações e paixões. Quanto a mim, associo, explicitamente, a tese favorável à ideia de que o referente último da representação historiadora é o vivente antigo, atrás do ausente de hoje na história, à mudança de paradigma que, na 'guinada crítica' dos Annales dos anos 80, promoveu o que se pode chamar de 'paradoxo do ator'. A história visa não apenas ao vivente de outrora, na retaguarda do morto de hoje, mas ao ator da história decorrida, desde que se decida 'levar a sério os próprios atores' ${ }^{44}$.

Ao tomar a experiência, indeterminada e singular, como referente histórico, a história social renovada coloca o acento sobre os atores históricos e sobre o processo de constituição do social. Essa grande virada da história social vincula-se de forma destacada às propostas de interpretação da ação situada advindas de diferentes hermenêuticas, com destaque para as contribuições de Paul Ricoeur e Reinhart Koselleck. Ao substituir a explicação a partir da imputação de um modelo social pelo trabalho de compreensão do processo de constituição das formações sociais, a

${ }^{44}$ RICOEUR, Paul. A memória, a história, o esquecimento..., p. 396. 
história social parece ser, paradoxalmente, a matriz historiográfica que leva mais longe o trabalho de apropriação das novas perspectivas teóricas que fomentam a historiografia na entrada do século: das categorias sociais à sociedadeprocesso/experiência.

\section{$\operatorname{son} 2$}

\section{RESUMO}

Em oposição à hegemonia exercida pelos Annales e pela história social-econômica, nas últimas décadas pode-se observar uma pluralização da produção historiográfica francesa. O volume de publicações na área da história cultural, política e de história do tempo presente aumentou consideravelmente, levando a uma reformulação dos fundamentos da própria história social. Algumas obras-chave servem com referência para cada um dos campos: Pour une histoire politique dirigida por René Rémond, publicada em 1988; Pour une histoire culturelle, dirigida por Jean-Pierre Rioux e Jean-François Sirinelli de 1997 e Les formes de l'expérience: une autre histoire sociale, organizada por Bernard Lepetit em 1994 são as principais delas. Nosso objetivo, portanto, é o de apresentar os principais aspectos da pluralização da produção historiográfica nas décadas finais do século XX. Buscaremos também destacar elementos comuns das diversas áreas, como o foco no tempo presente e a crescente apropriação da filosofia de Paul Ricoeur como fundamentação teórica para os historiadores.

Palavras Chave: Historiografia; Annales;

Teoria da história.

Artigo recebido em 29 ago. 2016.

Aprovado em 16 mai. 2018.

\section{ABSTRACT}

In opposition to the hegemony exercised by the Annales and social-economic history in recent decades, one can observe a French historiography pluralization. The amount of publications in the field of cultural history, politics and history of present time has considerably increased, leading to a reformulation of social history foundations itself. Some key works serve as reference to each field: Pour une histoire politique directed by Rene Remond, published in 1988; Pour une histoire culturelle, directed by Jean-Pierre Rioux and Jean-François Sirinelli in 1997 and Les formes de l'expérience: une autre histoire sociale, organized by Bernard Lepetit in 1994 are the leading of them. Our goal, therefore, is to present the main aspects of historiography pluralization in twentieth century's final decades. We also seek to highlight common elements of different areas, such as the focus on the present time and the increased ownership of Paul Ricoeur's philosophy as theoretical foundation by the historians.

Keywords: Historiography; Annales; Theory of history. 